\title{
Strategic Maneuvering in Mathematical Proofs
}

\author{
Erik C. W. Krabbe
}

Published online: 6 May 2008

(C) The Author(s) 2008

\begin{abstract}
This paper explores applications of concepts from argumentation theory to mathematical proofs. Note is taken of the various contexts in which proofs occur and of the various objectives they may serve. Examples of strategic maneuvering are discussed when surveying, in proofs, the four stages of argumentation distinguished by pragma-dialectics. Derailments of strategies (fallacies) are seen to encompass more than logical fallacies and to occur both in alleged proofs that are completely out of bounds and in alleged proofs that are at least mathematical arguments. These considerations lead to a dialectical and rhetorical view of proofs.
\end{abstract}

Keywords Argumentation - Blunder - Fallacy - False proof - Mathematics · Meno · Pragma-dialectics · Proof · Saccheri · Strategic maneuvering · Tarski

\section{Introduction}

The purport of this paper ${ }^{1}$ is to show that concepts from argumentation theory can be fruitfully applied to contexts of mathematical proof. As a source for concepts to be tested I turn to pragma-dialectics: both to the Standard Theory and to the Integrated Theory.

The Standard Theory has been around for a long time and achieved its final formulation in 2004 (Van Eemeren and Grootendorst 1984, 1992, 2004). According to the Standard Theory argumentation is a communication process aiming at

\footnotetext{
${ }^{1}$ The paper was first presented at the NWO-conference on "Strategic Manoeuvring in Institutionalised Contexts", University of Amsterdam, 26 October 2007.

E. C. W. Krabbe $(\bowtie)$

Faculty of Philosophy, University of Groningen, Oude Boteringestraat 52, 9712 GL Groningen,

The Netherlands

e-mail: e.c.w.krabbe@rug.nl
} 
the resolution of a difference of opinion (which could consist of an opinion held by one party, but not by the other, though the other does not adhere to the opposite point of view either). Argumentative communication takes place in explicit dialogical interaction or in monological texts or speeches, which are however regarded as containing an implicit dialogue between author and addressee. Thus the primary model for argumentation, used both for analysis and evaluation, is a dialogical model: the model of critical discussion. Ideally, a discussion should contain four stages (which may be repeated in subdiscussions). In the confrontation stage the difference of opinion is defined and clarified. In the opening stage it is determined what common ground is available to start the argumentation stage, which consists of an exchange of arguments and criticisms. In the concluding stage the result of the discussion is determined. The procedure is further regulated by a number of rather technical rules (Van Eemeren and Grootendorst 1984, 2004) the effect of which can be summarized in a practical code of conduct consisting of 10 commandments (Van Eemeren and Grootendorst 1992, 2004). Violations of these rules are fallacies; they threaten the resolution process. Among the fallacies thus defined, one finds not only logical fallacies (infringements of the Validity Rule: Reasoning that in an argumentation is presented as formally conclusive may not be invalid in a logical sense (2004, p. 193)), but many other disruptions of the resolution process, such as failing to take on one's burden of proof, or arguing for something different than the point of view one is supposed to argue for (ignoratio elenchi), or substituting one's authority for argument (argumentum ad verecundiam). In order to apply the Standard Theory to mathematical proofs, it must first be established that, at least in some contexts, proofs can be regarded as arguments; a matter that will be briefly discussed in Sect. 2.

The Integrated Theory (Van Eemeren and Houtlosser 1999a, b, 2002, 2004, 2005) starts from the observation that, usually, people argue not only with the objective of resolving a difference of opinion, but also with that of resolving it in their own favor: they pursue the rhetorical ${ }^{2}$ objective of having their point of view accepted by the other (1999a, p. 164). When arguers attempt to pursue both objectives at the same time, this leads to strategic maneuvering. To get a better grasp of the analysis of argumentative discourse, the Integrated Theory extends the Standard Theory by rhetorical considerations, all the same maintaining the norms of the Standard Theory where evaluation is concerned. When strategic maneuvering oversteps these bounds, it is said to have been derailed, and a fallacy has been committed (2002, pp. 141-143). Strategic maneuvering that remains within the bounds of the Standard Theory can still be suboptimal with respect to the second objective. In that case, no fallacies are committed, but one is confronted by flaws or blunders (2002, p. 142; Walton and Krabbe 1995, p. 25).

The point of view of the Integrated Theory can be extended by introducing yet other objectives that an arguer may simultaneously pursue. For mathematical proofs (presuming them to be arguments), one may think of epistemic and didactic objectives that figure in various contexts of proof and might interfere with the two objectives mentioned above. This will be explored in Sect. 3 .

\footnotetext{
${ }^{2}$ Elsewhere I argued that this objective can be seen as a (secondary) dialectical objective (Krabbe 2004).
} 
After having thus obtained a rough notion of what various arguers try to achieve when they set out to prove a theorem, one will find in Sect. 4 a number of examples of strategies, derailments, and blunders, grouped according to the four stages mentioned above. Derailments will be shown to occur both within and beyond the bounds of what may be called a "mathematical argument". Section 5 contains some conclusions and adds some remarks on the concept of proof.

\section{Proofs and Arguments}

Is there any strategic maneuvering in mathematical proofs? If, on the one hand, we use the term 'strategic maneuvering' in the way it is used in the Integrated Theory and, on the other hand, stick to the notion of mathematical proof as a conclusive establishment of a theorem, flawless and unassailable for all ages_-what I shall call 'the austere concept of proof' - then the two seem miles apart. The habitat of strategic maneuvering is a context of controversy and critical testing where one party tries to steer the resolution process so as to serve his personal aims. According to the austere notion of proof, there are no personal aims, and establishing the truth is the only goal in sight. Johnson $(2000$, p. 232) claims that mathematical proofs are no arguments. If that is so, there would be no place for strategic maneuvering in the sense of the Integrated Theory either. But of course, all depends on how one defines these notions of argument and proof. Dove (2007) points out that the characteristics of proof assumed by Johnson do not concur with mathematical practice as shown in Imre Lakatos's famous example about the polyhedra (Lakatos 1976). Lakatos's conception of proof is argumentative and admits, even requires, a dialectical tier. So there are conceptions of proof, connected with mathematical practice, that place proofs within the scope of argumentation theory and therefore, potentially, within the scope of strategic maneuvering. In an earlier paper (Krabbe 1991, 1997) I also maintained that ordinary informal mathematical proofs are arguments. It should be noted that mathematical proofs, even the axiomatic ones, are normally informal. Formal proofs (written in a formal language and constructed according to formalized derivation rules, as in formal natural deduction) are a logician's gadget.

Let it be granted that mathematical proofs are (normally ${ }^{3}$ ) arguments. But mathematical proofs, being mathematical arguments, also display some special features in that they are situated in a specific semi-institutionalized scientific context in which arguments are supposedly subject to requirements that are additional to those applying to arguments in general. Not every argument, not even every argument about mathematical propositions, is a mathematical argument, let alone a mathematical proof. One may cite Fermat's Last Theorem and invoke the authority of mathematicians to argue that it is true. This may be a good argument, but it is not a mathematical argument, and not a mathematical proof. It is not a mathematical argument because it is not using the mathematical way of reasoning. Aristotle would say that it is not according to the art (kata tên technên). In each discipline there are certain conventions

\footnotetext{
3 Proofs that are not arguments include: immediate proofs (where there is no reasoning), formal proofs, and proofs in a context where there is no difference of opinion (see Sect. 3).
} 
to which an argument must conform to be an argument within the discipline. For instance, in medicine you cannot reason as in philosophy. Aristotle's example is wellknown: "if someone were to deny that it is better to take a walk after dinner because of Zeno's argument, ${ }^{4}$ it would not be a medical argument" (SE 11, 172a8-9; Aristotle 1965 , p. 65). But even those arguments that are really mathematical can fail to count as proofs. They can fail for two reasons. First, they may contain a fallacy, and therefore be no more than a false (or invalid) proof, and not a real proof. ${ }^{5}$ According to Aristotle "the man who draws a false figure" (pseudographôn) does not prove anything, and "his process of reasoning is based on assumptions which are peculiar to the science but not true" (Top. 1.1, 101a10,13-15; Aristotle 1976, p. 275). Thus his argument may be counted as a mathematical argument, but not as a proof. The second way in which a mathematical argument can fail to be a proof is that it fails to comply with some further additional requirements. But people differ on what these additional requirements are. Aristotle tells us that by proof or demonstration (apodeixis) he means deductive reasoning ('syllogism') which gives us scientific knowledge. Such demonstrative knowledge, however, can only be obtained if one proceeds by deductive reasoning "from premises which are true, primary, immediate, better known than, prior to, and causative of the conclusion" (Anal. post. 1.2, 71b17-22; Aristotle 1976, p. 31). Thus Aristotle places proof within a foundationalist philosophy of science. There are other options, some of which make the notion of proof a relative notion: a proof is a proof for a given person and perhaps not for someone else. According to John Corcoran there are "two basic issues: are the premises known to be true by the given person? And does the chain of reasoning deduce the conclusion from the premise-set for the given person?" (Corcoran 1989, p. 25). In my proposal (Krabbe 1991, 1997), in order that an argument be a proof for a given person, the starting points of the (underlying) critical discussion must be assertions and not merely concessions of that person, and all the possible dialectic options for that person must be followed through, not merely those that happen to occur to that person; of course there must be no fallacies, and the proponent of the theorem proved (the protagonist) must be the winner of the discussion.

For the purposes of this paper, it will not be necessary to make a choice between the different sets of additional requirement that are meant to distinguish mathematical proofs from mere mathematical arguments. But any set of additional requirements making the notion of proof relative to the addressee seems to bring proofs even more clearly within the scope of argumentation theory, and in particular within the scope of the theory of strategic maneuvering (the Integrated Theory).

\section{Contexts of Proof}

Supposing that mathematical proofs are normally arguments, we may (1) regard them as (implicit) critical discussions, and (2) investigate whether certain modes of strategic maneuvering are characteristic for such proofs and (3) how these modes

\footnotetext{
4 A philosophical argument that motion is impossible.

5 On this point the grammar of the term 'proof' differs from that of the term 'argument', for an invalid argument is still an argument.
} 
may lead to blunders and derailments (fallacies). In this, one should keep in mind that mathematical proofs come in kinds as to their objectives and the audiences they are aimed at. They also occur in different types of dialogue (Walton and Krabbe 1995), here seen as activity types (Van Eemeren and Houtlosser 2005), and display different functions of reasoning (Krabbe and Van Laar 2007). As a first list of contexts of proof, I propose the following:

1. thinking up a proof to convince oneself of the truth of some theorem;

2. thinking up a proof in dialogue with other people (inquiry dialogue; probative functions of reasoning);

3. presenting a proof to one's fellow discussants in an inquiry dialogue (persuasion dialogue embedded in inquiry dialogue; persuasive and probative functions of reasoning);

4. presenting a proof to other mathematicians, e.g. by publishing it in a journal (persuasion dialogue; persuasive and probative functions of reasoning);

5. presenting a proof when teaching (information-seeking and persuasion dialogue; explanatory, persuasive, and probative functions of reasoning).

These contexts of proof are all very different and a proof that succeeds in one context may well fail in some others. Persuasive functions aim at convincing the other. These functions are argumentative in the sense that, given some difference or conflict, they serve to overcome doubt of an interlocutor (Krabbe and Van Laar 2007 , p. 31). ${ }^{6}$ So, whenever in a proof the reasoning displays persuasive functions, the proof can be regarded as an argument. Probative functions aim at extending the knowledge of some company or community; they are not argumentative. Explanatory functions, which are not argumentative either, aim at enhancing understanding. In all contexts listed, except the first, the reasoning in proofs has a probative function: extending available knowledge. In the first context it has not this function, but only that of extending one's personal knowledge. In all contexts, except the first two, it also has persuasive functions, mostly that of convincing others of the truth of some theorem. In the first context, however, there is no other, whereas in the second context the others participate in making the proof. Thus in these two contexts the reasoning is not argumentative, and one should say that the proofs (as speech or thought events) are not arguments, though the proofs as products could of course be used argumentatively in another context, and then be arguments. That proofs in teaching are presented in a context of informationseeking dialogue and have explanatory functions will not be surprising. But it should be stressed that in teaching there is also persuasion dialogue with persuasive and even probative functions in play.

The last point, that mathematical instruction involves persuasion dialogue, and is therefore argumentative, can be illustrated by the famous passage in Plato's Meno (82b-85b; Plato 1997) where Socrates teaches a slave how, for a given square, to find the length of the side of a square with twice the area of the given square. Socrates proposes to do so without passing on any information to the slave (without

\footnotetext{
${ }^{6}$ Other argumentative functions of reasoning mentioned by Krabbe and Van Laar are the polemic functions (in eristic dialogue) and the directive functions (in negotiation).
} 
Fig. 1 Doubling the square

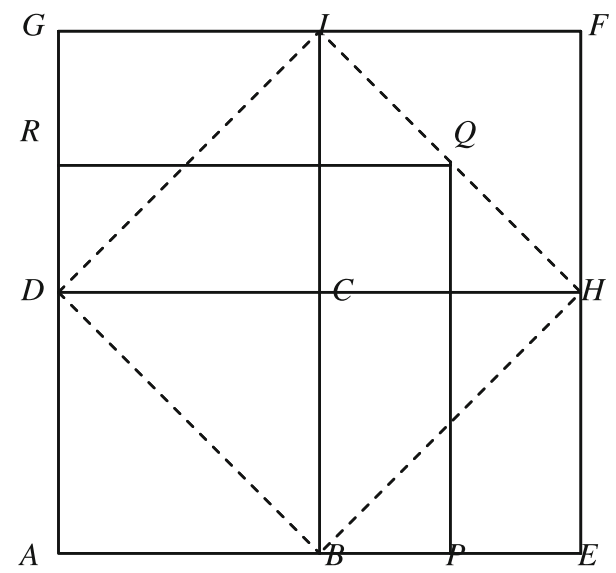

information-seeking dialogue), instead he will just ask questions. Socrates' ultimate, philosophical intention is to demonstrate that so-called learning is a kind of memory of what one knew in a life before this one. The given square $(A B C D)$ has a side $(A B)$ with a length of two feet (Fig. 1).

The slave is at first quite sure that in order to double the area one needs to double the length of the side $(A B$ to $A E)$. After some leading questions by Socrates, he realizes that four feet is too much. Since two feet is too little, he opts for three feet $(A P)$. More questioning makes him realize that a square with a three foot side would have an area of nine square feet $(A P Q R)$, one too many. Then Socrates induces the slave to draw a figure of a square of sixteen square feet $(A E F G)$ divided in four parts of four square feet each $(A B C D, B E H C, C H F I, D C I G)$ and asks whether the diagonals of the smaller squares (DB, etc.) do not divide these squares in two equal parts. Some more questioning elicits the answer: the side of the square with an area of eight square feet must have the length of this diagonal (square $D B H I$ ). Though I do not think this demonstration is very successful in demonstrating a life before this life (the questions actually pass on lots of information), it does show how in teaching mathematics presenting a proof is something more than passing on the information. The student is to think through the proof for him or herself and to become convinced of its cogency as well as of the truth of the conclusion. Each step in the proof needs to be checked by the student, something Socrates achieves by his questioning.

So proof in a didactic context has not just explanatory functions, but also persuasive ones. The persuasive strategy used is that of letting the student give wrong answers first and let him (with some help) discover that these answers are wrong, thus strengthening his commitment to the right answer in the future. Notice that going through the rejection of wrong answers first is in itself not necessary for a valid proof; but it is permissible, and here contributes to the specific aims of the teacher. So we may say it is a case of nonfallacious strategic maneuvering which combines the objective of valid argument with that of making a student master a particular piece of mathematics. 


\section{Proofs in Stages}

Assuming again that mathematical proofs are arguments, and that pragmadialectical theory enriched by the theory of strategic maneuvering applies to all kinds of arguments, we should be able to identify in proofs the four stages of critical discussion, and to investigate for each stage what kind of strategic maneuvering would be typical for that stage of the proof and to what blunders and derailments these kinds of maneuvering are typically prone.

\subsection{The Confrontation Stage}

In the confrontation stage, authors of proofs must formulate what they set out to prove. According to the rules of critical discussion they must do so in a clear and unambiguous way. In order to attract attention and to convince as many of their colleagues (or students) of the truth of the theorem it is also important for them to formulate the theorems in simple and attractive terms. To achieve this a well-known strategic maneuver is to state the theorem in terms that appear to be simple and familiar but actually refer to concepts that are quite complex. The complexities behind these terms are then covered by definitions that accompany the theorem. For instance, the completeness theorem is simply formulated as: Every valid formula is provable. A formulation that calls for extensive explanations of what is meant by 'formula', 'valid', and 'provable'.

This strategy is certainly commendable. It would be a strategic blunder (a forgoing of a legitimate advantage) if one did not use it. Yet, it could be a derailment if an author framed his terms and definitions so as to let his theorems appear to be relevant beyond mathematics, suggesting applications in the real world that are not really feasible. For instance mathematical concepts of space, probability, preference, and validity may suggest corresponding concepts from daily life (which may, however, diverge among themselves), and the mathematics using these terms may yield nice theorems which disclose interesting parallels between mathematical and common conceptions of space, etc., but to presume that the mathematics applies to these concepts as commonly understood would be premature. In the hands of mathematicians such concepts may also change into something quite different. As Goethe said: Die Mathematiker sind eine Art Franzosen: redet man zu ihnen, so übersetzen sie es in ihre Sprache, und dann ist es alsobald ganz etwas anders. ${ }^{7}$ (Goethe 1949, p. 660, nr. 1279.) Whether such tactics are fallacious depends, however, on further circumstances, such as the kind of audience. It would be fallacious to hide the changes in the concepts and to try to make the audience believe there are not any.

\subsection{The Opening Stage}

In the opening stage, the author should, in a context of axiomatic proof, state or indicate her axioms, or, if the context is nonaxiomatic, the general frame that is

\footnotetext{
${ }^{7}$ Mathematicians are a kind of Frenchmen: If one speaks to them, they will translate it into their language and then it is in no time something totally different.
} 
presupposed in the proof. Is the Axiom of Choice accepted? Does the theorem pertain to the real numbers or to complex numbers? Of course it would be wise to choose a frame or axiomatic setting in which the proof can be completed, but which is also attractive to the audience. The author may blunder by indicating a frame in which the theorem later appears not to hold, or commit a fallacy by sticking to the theorem in such a frame. In a context of teaching that uses nonaxiomatic proofs, strategic maneuvering should yield starting points that are close enough to the theorem to prove it by a reasonably short proof, but distant enough to avoid triviality. Also, the starting points should be comprehensible to the students. It would, of course, be a derailment of such maneuvering to start from false principles in order to facilitate the proof.

\subsection{The Argumentation Stage}

In the argumentation stage, the author should try to make her proof neither too sketchy nor to fine-meshed. The degree of detail in the proof must be adapted to the audience. Is the proof meant to convince an expert or a student? And if a student, is it a mathematically mature student, or not? This makes a great difference: what constitutes a proof for the one does not necessarily constitute a proof for the other. Failure to adapt the proof to the audience in this respect would constitute a blunder, and in more serious cases it could be a derailment. The fallacy would then be one of evading the burden of proof, because when the steps in the reasoning are to big or to complicated for the audience to grasp no argument has been given that constitutes a proof for that audience, and the audience's implicit critical questions remain unanswered.

The author should also attempt to construct an attractive division of work between the proofs of lemmas and the proof the theorem itself (based on the lemmas). Elements of surprise may be introduced to make the proofs more attractive, and the greatest surprise should be left for the proof of the main theorem, if possible. This part of the rhetoric of proofs reminds one of a general tactic of argumentation, recommended by Aristotle (Top. 8.1) known as krupsis, or the hiding of one's intentions about the argument's set-up. Generally, an elegant proof will be preferred over a messy one. Missing opportunities to make the proof more attractive amounts to blundering, whereas substituting elegance for validity would constitute a derailment. A serious fallacy would be committed, were one to use a theorem to establish a lemma needed for the theorem's own proof (begging the question), whereas loops in a proof that are merely superfluous, would constitute mere blunders.

Leaving routine parts of the proof to the audience, constitutes a recommendable tactic since it will include the audience in the enterprise of establishing the theorem, and thus strengthen their conviction in the end. But it would be a blunder to leave tasks to the audience that are so demanding as to upset them, rather than to make them participants in proof construction. (It is a blunder relative to the objective of convincing the audience by rational means, not relative to the objective of giving the audience some training.) If a task cannot be performed at all, to ask the audience 
to perform this task would be a derailment of the strategy of leaving tasks to the audience. But also, if the task can in principle be performed, but arguably not by the intended audience (at least not by means of a reasonable effort and within a reasonable period of time), the strategy gets derailed. This would once more constitute a fallacy of evading the burden of proof. ${ }^{8}$

The well-known strategy of proof called reductio ad absurdum can lead to a derailment when one is too eager to disprove an hypothesis. A vulgar type of this derailment would consist in annoying one's audience by an endless chain of derivations from the hypothesis (to be refuted) leading nowhere, making them grant the absurdity of the hypothesis rather than listen any longer. This tactic, known as reductio ad nauseam, would not be "according to the art". Another vulgar tactic would consist in claiming to have reached an absurdity when there is none.

However, a claim of having reached an absurdity where there is none could also occur in a proof according to the art, though it uses a false assumption about what constitutes an absurdity. A serious case of this can be found in the purported proof of Euclid's fifth postulate by (Giovanni) Girolamo 9 Saccheri (1667-1733). As many before him, Saccheri wanted to show that this postulate is superfluous by proving it from the other Euclidean axioms (Saccheri 1733). To achieve this he chose a strategy of reductio ad absurdum. More specifically he purported to use that of the consequentia mirabilis (to prove $P$, derive $P$ from the supposition that not- $P$ ) of which he had been a champion for years (Kneale and Kneale 1962, pp. 345-347, 380). Thus he added the denial of the fifth postulate to the other axioms and sought to derive the fifth postulate from that.

Now the fifth postulate is, granted the other postulates and some traditional features of geometrical reasoning, equivalent to the Axiom of Parallels: given a line $l$ and a point $P$ not on $l$, there is exactly one line through $P$ that is parallel to $l$ (i.e. in the same plane and having no point in common with $l$ ). The denial of the Axiom of Parallels, for a given $l$ and $P$ not on $l$, leaves two possible suppositions: (1) No line through $P$ runs parallel to $l$. (2) More than one line does. ${ }^{10}$ Saccheri managed to derive the fifth postulate from (an equivalent of) the first supposition (his Proposition XIII; Beth 1929, p. 21), thus reducing this supposition to absurdity; however, in the part of the proof that starts from (an equivalent of) the second supposition he derived a number of consequences that are absurd merely from a Euclidean point of view, but became later known as theorems of hyperbolic geometry (discovered by Bolyai, Lobachevsky, and Gauss). When reaching the consequence that there were two different straight lines approaching one another asymptotically and thus having a common perpendicular at a common point in the infinite, Saccheri decided that this contradicted the nature of straight lines and falsely inferred the absurdity of (2), thus completing the "proof" of the fifth postulate (Proposition XXXIII; Beth 1929, pp. 25-26). This was a mistake, but it

\footnotetext{
${ }^{8}$ It is a common experience of math students that authors of textbooks sometimes exasperate their readers by leaving not the routine parts but the more difficult parts of a proof to them.

9 Often: Gerolamo.

${ }^{10}$ Clearly, for a given $P$ and $l$, there are precisely three possible suppositions: no parallel, exactly one, or more than one. It should be remarked that when one of these suppositions holds, the same can be shown to hold for all other points $Q$ and lines $m(Q$ not on $m)$ of the plane.
} 
doesn't make Saccheri's work nonmathematical. His work is still conforming, I would say, to the art (in contrast to the vulgar reductions, discussed above). It was a sad mistake, for strange enough Saccheri, having actually worked in non-Euclidean geometry, failed to discover it. According to Beth (1965, p. 12) this was "one of the most tragic occurrences in the history of science-one can without hesitation say: in the whole history of the world; tragedy does not necessarily presuppose that blood is spilt- that Saccheri let himself be carried along by his desire to prove the axiom of parallels."

Thus derailment of strategies may occur both in purported proofs that are not according to the art and in those that are so in principle, but display some flaw or other. Another example of the first kind is constituted by so-called "proofs by lack of space on the blackboard". Here the teacher scribbles all over the blackboard, until he arrives at the bottom right corner, and then skips the last and most essential part of the proof by lack of space. Nowadays, these tactics have become obsolete by lack of blackboards. Another fallacious tactic, would be, not to present a proof at all, but to claim that one has one at home (stored in one's desk). Of course this may, in some contexts, be a good argument for the truth of the theorem, but it does not constitute mathematical proof, since it is not a mathematical argument. ${ }^{11}$

Examples of the second kind (according to the art, but displaying some flaw) include cases of flaws discovered in mathematical work, among them cases of notorious errors by famous mathematicians such as Leonard Euler's (1707-1783) elegant but incomplete proof that Fermat's Last Theorem ${ }^{12}$ holds for exponent $n=3$ (1770) which contained a serious gap, even though it may be that Euler actually had a proof (Edwards 1977, pp. 39-40, 45); or the general "proof" of Fermat's Last Theorem that Gabriel Lamé (1795-1870) presented to the Paris Academy in 1847, in which he unwarrantedly presumed the Fundamental Theorem of Arithmetic (unique factorization into primes) to hold for certain complex numbers (Edwards 1977, pp. 76-77) ${ }^{13}$; or Andrew Wiles's presentation of an alleged proof for Fermat's Last Theorem in 1993, which contained a subtle error (corrected the following year). These examples illustrate how the tension between, on the one hand, the objective of presenting proofs conforming to the norms of critical discussion (including logical requirements) as well as to the special requirements of the art of mathematics and, on the other hand, such objectives as being successful in proving a particular theorem, presenting an elegant proof, or simply presenting it before others do, can lead to derailments of strategic maneuvering.

A curious case of derailment, related by Haskell Curry (1900-1982; 1963, p. 88), is that of Alfred Tarski (1901-1983) who formulated in an unfamiliar notation what he thought were E.V. Huntington's axioms of Boolean algebra (Tarski 1956, corrected version 1983). In fact the published postulates did form an axiom set, not of Boolean algebra, but of something else. Now, this error went unnoticed from the

\footnotetext{
11 Moreover, even as a nonmathematical argument it could be a fallacy (argumentum ad verecundiam).

12 Fermat's Last Theorem: There are no positive integers $x, y, z, n(n>2)$ such that $x^{n}+y^{n}=z^{n}$.

13 The story that Ernst Kummer (1810-1893) succumbed to a similar illusion before discovering the ideal complex numbers (Bell 1965, p. 522) is probably apocryphal (Edwards 1977, p. 80).
} 
original Polish version into German and English translations, but was finally discovered by accident in 1956. According to Curry such a situation would have been inconceivable had the axioms been expressed in a more familiar notation. Now Tarski was very surprised that no one had made the discovery before: "It seems strange that so far I nor anybody else has noticed the mistake (though the paper has probably been read by a number of people)" (quoted by Curry 1963, p. 88). The moral of the story is that one should not suppose that people read one's paper. Moreover, the paper was 127 pages long and the error consisted of just one misprinted subscript. If this is a case of derailment, we should dub it a microderailment.

Among the examples presented thus far, those that reason according to the art (though making a mistake) seem to take mathematics seriously, whereas those that do not conform to the art don't. But one could be very serious in proposing a proof that is completely out of bounds. Thus I remember a student contesting the theorem that through one point $P$ on the circumference of a circle there can be drawn only one tangent line to the circle. To show that more tangents can be drawn, he drew a very fat point on the circumference and let a line wobble on this fat point (Fig. 2). The student may have been serious, but his proof was not according to the art.

The same holds for some so-called false proofs (or invalid proofs) of false or nonsensical propositions, for instance the proof in the Wikipedia that $\infty=1 / 4$, can in some contexts be understood as a serious attempt to do mathematics and not just as a kind of joke. But then, by taking $\infty$ for a number, the alleged proof gets completely derailed and fails to be mathematical (see Appendix).

On the contrary, the proof in the Wikipedia that $4=5$ and the one that any angle is zero (see Appendix) can hardly be understood as serious, but strangely enough these proofs do conform to the art (just making a mistake at some point; see Appendix). The same holds for the notorious proof by mathematical induction that all horses have the same color:

In a group consisting of only one horse all horses have the same color, there being only one horse. Suppose that in any group of $n$ horses all horses have the same color. Take an arbitrary group of $n+1$ horses. Take away one horse $h$. What is left is a group of $n$ horses. According to the supposition they must all have the same color $C$. It only remains to prove that horse $h$ also has color $C$. Now put $h$ back into the group and take away another horse. Again we have a group of $n$ horses. According to the supposition they must have the same color. Since the others have color $C, h$ must have color $C$ as well. So all horses

Fig. 2 More tangents

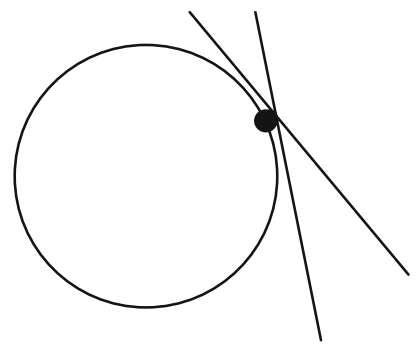


in the group of $n+1$ horses have the same color (color $C$ ). Since this group was arbitrarily chosen, any group of $n+1$ horses consists of horses of the same color. By mathematical induction, for each $n$, in any group of $n$ horses all horses have the same color. Let the number of horses in the world be $m$, then all horses together form a group of $m$ horses and must all have the same color, QED.

This proof uses mathematical induction, which in itself is conforming to the art, but in its present application contains a flaw. The puzzle only works with those acquainted with mathematical induction, but not too experienced in its application. In fact most people, being unfamiliar with this method, use to attack parts of the proof that are impeccable, inexperienced students may be really puzzled for some time, whereas experienced mathematicians may not be challenged. This nicely illustrates how the usability of a particular strategy depends on the audience.

\subsection{The Concluding Stage}

In the concluding stage, it is advisable to clearly indicate that the proof has ended. Traditionally, this was effected by repeating the theorem, letting it be followed by 'QED', but at some point this went out of fashion. It is however crucial to indicate the end of proof, otherwise people may continue to look for a proof when the proof is actually finished, and thus are likely to miss it. Nowadays, various typographical devices, such as a bold dot or a crossed square, are in use. At the same time, such a symbol stands for the proponent's claim to have resolved the difference of opinion in his favor. The proponent can derive side-benefits from this happy conclusion by adding reflections about the method of proof and the ways difficulties were dealt with, and also by stressing further results that may be derived from either the theorem (its corollaries) or the method of proof (which could be used in other cases). It would be a blunder to overdo this, and it would be a serious derailment if the proponent started bragging about his proof prematurely, without having proved what had to be proved, though perhaps having proved something else (ignoratio elenchi).

\section{Conclusion}

The dialectical and rhetorical view of proofs presented here contrasts with the austere concept of proof: the view of proofs as flawless and unassailable entities that are either there (success) or not (failure). According to the present view, proofs may be more or less successful, depending upon context and audience. We saw that what counts as a proof for some does not count as a proof for others. Some proofs are rather sketchy, leaving much room for questioning (or work for the reader, if the author is not there to answer questions), whereas others, by answering these questions, are developed to great dialectical depth.

But is a formalized proof not the natural limit of dialectical depth? It is true that the notion of a formalized proof is based on the idea of a proof without gaps 
(lückenlose Beweisführung, Gottlob Frege 1848-1925, 1879), i.e., a proof where no questions remain, since no intermediate steps are left out. Also, formalized proofs are flawless and unassailable. But by themselves they prove nothing: for this they need to be interpreted. The proofs of mathematical logic that carry conviction are not these formal objects, but the informal proofs about these objects, and these proofs are normally arguments.

Moreover, it is not true that a proof of greater dialectical depth is always the better proof. One can overdo the amount of detail, given a certain audience. This, as we saw, would constitute a blunder rather than a fallacy. But what if the details make it impossible to understand the proof?

Finally, the austere concept of proof cannot be saved by saying that the true proofs are the proofs for the experts. In contemporary mathematics the unity of the conceptual world has broken down. There is of course classical and intuitionistic mathematics, but also within classical mathematics there is a wealth of options for building an underlying set-theoretical universe (with or without the axiom of choice, with or without the continuum hypothesis, etc.). Nowadays mathematicians live in different mathematical universes (van Dalen 2006). So, even among experts, it is true that what constitutes a proof in someone's universe is no proof for some colleagues living in a different mathematical universe.

In constructing a proof, then, there is room for strategic maneuvering to combine one's allegiance to norms of critical discussion and to the special requirements and conventions of mathematics with other propensities, such as one's desire to complete the proof of a nice theorem and to convince the audience. Derailments correspond to dialectical fallacies, which include, but are not confined to, mathematical errors (and some types of which may be specific for attempts to present a mathematical proof), whereas blunders correspond to a suboptimal maneuvering within the bounds set by critical discussion and the art of mathematics.

Open Access This article is distributed under the terms of the Creative Commons Attribution Noncommercial License which permits any noncommercial use, distribution, and reproduction in any medium, provided the original author(s) and source are credited.

\section{Appendix}

\section{False Proofs}

Three false proofs that were mentioned in this paper appeared in the Wikipedia (Invalid Proof 2007). Paraphrases of these false proofs are given below.

\section{Proof that $\infty=1 / 4$}

To find the distance between, say -4 and 3 (the points $(-4,0)$ and $(3,0)$ on the $x$-axis) one calculates $3-(-4)$, which gives 7 . Generally, for points $(-a, 0)$ and $(b, 0)$ the distance is equal to $b-(-a)$. The whole $x$-axis runs from $-\infty$ to $\infty$, its length is therefore equal to $\infty-(-\infty)$. The same is true for the $y$-axis. The area of the plane must be equal to the product of the lengths of the two axes, i.e. $(\infty-(-\infty))^{2}$. Since 
the plane is infinite, we get: $\infty=(\infty-(-\infty))^{2}$, which can be simplified into $\infty=(2 \infty)^{2}$. This yields to $\infty=4 \infty^{2}$, from which we get $1=4 \infty^{2} / \infty$, which simplifies into $1=4 \infty$, and finally yields the value of the infinite: $\infty=1 / 4$ (this can be checked by substituting $1 / 4$ for $\infty$ in the equation $\left.\infty=(\infty-(-\infty))^{2}\right)$, QED.

\section{Proof that $4=5$}

Nobody doubts the law of identity: $-20=-20$. Differently expressed: $25-45=$ $16-36$. Introducing factors one obtains the equivalent expression: $5^{2}-5 \times 9=$ $4^{2}-4 \times 9$. Adding $81 / 4$ to both sides gives: $5^{2}-5 \times 9+81 / 4=4^{2}-4 \times$ $9+81 / 4$. This can also be written as: $5^{2}-2 \times 5 \times 9 / 2+(9 / 2)^{2}=4^{2}-2 \times 4$ $\times 9 / 2+(9 / 2)^{2}$. Now applying the algebraic formula $a^{2}-2 a b+b^{2}=(a-b)^{2}$ twice (on the left, take $a=5$ and $b=9 / 2$, on the right take $a=4$ and $b=9 / 2$ ), you will get: $(5-9 / 2)^{2}=(4-9 / 2)^{2}$. Take the square root of both sides and you obtain: $5-9 / 2=4-9 / 2$. Adding $9 / 2$ on both sides gives: $5=4$. The law of symmetry of identities then gives $4=5$, QED.

\section{Proof that any angle is zero}

Let $\angle \mathrm{BAB}^{\prime}$ be any nonzero angle, where $\mathrm{B}$ and $\mathrm{B}^{\prime}$ are chosen so that they satisfy $\mathrm{AB}=\mathrm{AB}^{\prime}$. We shall show that, contrary to what is assumed, it must be the case that $\angle \mathrm{BAB}^{\prime}=0$. Construct a rectangle $\mathrm{ABCD}$ with side $\mathrm{AB}$, such that the points $\mathrm{C}$ and $\mathrm{D}$ lie outside $\angle \mathrm{BAB}^{\prime}$. Draw the perpendicular bisector of $\mathrm{CB}$, which intersects $\mathrm{CB}$ at $\mathrm{E}(\mathrm{CE}=\mathrm{EB})$. Draw $\mathrm{CB}^{\prime}$ and the perpendicular bisector of $\mathrm{CB}^{\prime}$, which intersects $\mathrm{CB}^{\prime}$ at $\mathrm{F}\left(\mathrm{CF}=\mathrm{FB}^{\prime}\right)($ Fig. 3).

These two perpendicular bisectors cannot be parallel (check). Let them intersect at G. Now, $\mathrm{BE}=\mathrm{CE}, \angle \mathrm{BEG}=\angle \mathrm{CEG}$, and $\mathrm{EG}=\mathrm{EG}$, so triangle $\mathrm{BEG}$ and triangle $\mathrm{CEG}$ are congruent. Consequently $\mathrm{BG}=\mathrm{CG}$. Similarly, since EG is also the perpendicular bisector of $\mathrm{DA}, \mathrm{AG}=\mathrm{DG}$. Since $\mathrm{AB}=\mathrm{DC}$, it follows that triangles $\mathrm{ABG}$ and $\mathrm{DCG}$ are congruent. Using triangles $\mathrm{B}^{\prime} \mathrm{FG}$ and $\mathrm{CFG}$, one proves, in a similar way, consecutively that $\mathrm{B}^{\prime} \mathrm{G}=\mathrm{CG}$ and that (because $\mathrm{AG}=\mathrm{DG}$ and $\mathrm{DC}=\mathrm{AB}=\mathrm{AB}^{\prime}$ ) triangles $\mathrm{DCG}$ and $\mathrm{AB}^{\prime} \mathrm{G}$ are congruent. From these two congruencies we derive that triangles $\mathrm{ABG}$ and $\mathrm{AB}^{\prime} \mathrm{G}$ are also congruent. Hence $\angle \mathrm{GAB}=\angle \mathrm{GAB}^{\prime}$. But then $\angle \mathrm{BAB}^{\prime}=\angle \mathrm{GAB}^{\prime}-\angle \mathrm{GAB}=0$. Thus the initial supposition that $\angle \mathrm{BAB}^{\prime}$ be a nonzero angle leads to a contradiction and we must conclude that nonzero angles do not exist.

Fig. 3 The vanishing angle

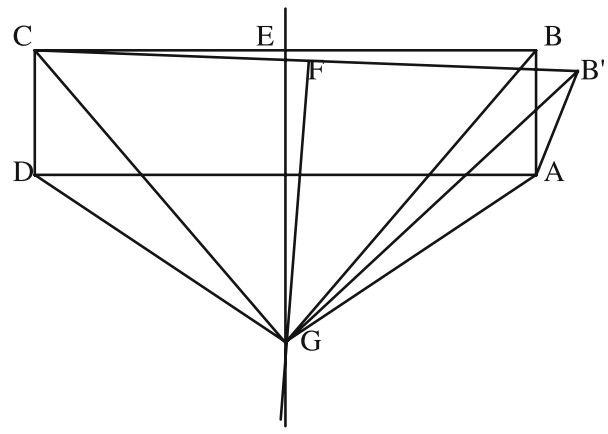




\section{References}

Aristotle. 1965. On sophistical refutations (trans: Forster, E.S.). In Aristotle, On sophistical refutations; On coming-to-be and passing-away; On the cosmos. Cambridge, MA: Harvard University Press and London: William Heinemann (The Loeb Classical Library 400/442)[First ed. 1955].

Aristotle. 1976. Posterior analytics; Topica (trans: Trendennick, H., Posterior analytics; trans: Forster, E.S., Topica). Cambridge, MA: Harvard University Press and London: William Heinemann (The Loeb Classical Library 391) [First ed. 960].

Bell, E.T. 1965. Men of mathematics, vol. 2. Harmondsworth: Penguin Books (Pelican Books A 277) [First ed. 1937].

Beth, E.W. 1965. Mathematical thought. Dordrecht: Reidel.

Beth, H.E.J. 1929. Inleiding in de niet-Euclidische meetkunde op historischen grondslag [Introduction to non-Euclidean geometry on a historical basis]. Groningen: Noordhoff.

Corcoran, J. 1989. Argumentations and logic. Argumentation: An International Journal on Reasoning 3 : $17-43$.

Curry, H.B. 1963. Foundations of mathematical logic. New York: McGraw-Hill.

Dove, I.J. 2007. On mathematical proofs and arguments: Johnson and Lakatos. In Proceedings of the sixth conference of the international society for the study of argumentation, ed. F.H. van Eemeren, J.A. Blair, Ch.A. Willard, and B. Garssen, 347-351. Amsterdam: Sic-Sat, International Center for the Study of Argumentation.

Edwards, H.M. 1977. Fermat's last theorem: A genetic introduction to algebraic number theory. New York: Springer.

Euler, L. 1770. Vollständige Anleitung zur Algebra. St. Petersburg.

Frege, G. 1879. Begriffsschrift, eine der arithmetischen nachgebildete Formelsprache des reinen Denkens. Halle: Louis Nebert.

Goethe, J.W. von. 1949. Maximen und Reflexionen. In J.W. von Goethe, Die Wahlverwandtschaften, Die Novellen, Die Maximen und Reflexionen, ed. E.R. Beutler. Zürich: Artemis. (Gedenkausgabe der Werke, Briefe und Gespräche 9).

Invalid Proof. September 10, 2007, 14: 36. In Wikipedia. Retrieved October 10, 2007, from http://en.wikipedia.org/wiki/Invalid_proof.

Johnson, R.H. 2000. Manifest rationality: A pragmatic theory of argument. Mahwah, NJ: Lawrence Erlbaum.

Kneale, W., and M. Kneale. 1962. The development of logic. Oxford: Clarendon.

Krabbe, E.C.W. 1991. Quod erat demonstrandum: Wat kan en mag een argumentatietheorie zeggen over bewijzen? [QED: To what extent can or may a theory of argumentation deal with proofs?] In Thema's in de Taalbeheersing: Lezingen van het VIOT-taalbeheersingscongres gehouden op 19, 20 en 21 december 1990 aan de Rijksuniversiteit Groningen, ed. M.M.H. Bax and W. Vuijk, 8-16. Dordrecht: ICG.

Krabbe, E.C.W. 1997. Arguments, proofs, and dialogues. In Dialogisches Handeln: Eine Festschrift für Kuno Lorenz, ed. M. Astroh, D. Gerhardus, and G. Heinzmann, 63-75. Heidelberg: Spektrum Akademischer Verlag [Translated and revised version of Krabbe (1991)].

Krabbe, E.C.W. 2004. Strategies in dialectic and rhetoric. In Argumentation and its applications, ed. H.V. Hansen, C.W. Tindale, J.A. Blair, R.H. Johnson, and R.C. Pinto. Proceedings of the conference organized by the Ontario society for the study of argumentation, May 17-19, 2001, University of Windsor, CD-ROM. Windsor, ON: OSSA.

Krabbe, E.C.W., and J.A. van Laar. 2007. About old and new dialectic: Dialogues, fallacies, and strategies. Informal Logic: Reasoning and Argumentation in Theory and Practice 27: 27-58.

Lakatos, I. 1976. Proofs and refutations: The logic of mathematical discovery, ed. John Worral and Elie G. Zahar. Cambridge: Cambridge University Press.

Plato. 1997. Meno (trans: Grube, G.M.A.). In Plato, Complete works, ed. J.M. Cooper and D.S. Hutchinson, 870-897. Indianapolis, IN: Hackett Publishing Company.

Saccheri, G.G. 1733. Euclides ab omni naevo vindicatus [Euclid freed from every birth mark]. Milan.

Tarski, A. 1956. The concept of truth in formalized languages. In Tarski, Logic, semantics, metamathematics: Papers from 1923 to 1938, 152-278 (trans: Woodger, J.H.). Oxford: Clarendon Press. 
Tarski, A. 1983. The concept of truth in formalized languages. In Tarski, Logic, semantics, metamathematics: Papers from 1923 to 1938, 152-278 (2nd ed., ed. and introd.: John Corcoran, trans: Woodger, J.H.). Indianapolis, IN: Hackett.

Van Dalen, D. 2006. Weet u dat zeker? Over (on)zekerheden in de wiskunde [Are you sure? About (un)certainties in mathematics]. Johann Bernoulli Lecture, Groningen, March 7th, 2006.

Van Eemeren, F.H., and R. Grootendorst. 1984. Speech acts in argumentative discussions: A theoretical model for the analysis of discussions directed towards solving conflicts of opinion. Dordrecht: Foris.

Van Eemeren, F.H., and R. Grootendorst. 1992. Argumentation, communication, and fallacies: A pragmadialectical perspective. Hillsdale, NJ: Lawrence Erlbaum.

Van Eemeren, F.H., and R. Grootendorst. 2004. A systematic theory of argumentation: The pragmadialectical approach. Cambridge: Cambridge University Press.

Van Eemeren, F.H., and P. Houtlosser. 1999a. Delivering the goods in critical discussion. In Proceedings of the fourth international conference of the international society for the study of argumentation, ed. F.H. van Eemeren, R. Grootendorst, J.A. Blair, and Ch.A. Willard, 163-167. Amsterdam: Sic-Sat.

Van Eemeren, F.H., and P. Houtlosser. 1999b. William the silent's argumentative discourse. In Proceedings of the fourth international conference of the international society for the study of argumentation, ed. F.H. van Eemeren, R. Grootendorst, J.A. Blair, and Ch.A. Willard, 168-171. Amsterdam: Sic-Sat.

Van Eemeren, F.H., and P. Houtlosser. 2002. Strategic manoeuvring in argumentative discourse: A delicate balance. In Dialectic and rhetoric: The warp and woof of argumentation analysis, ed. F.H. van Eemeren and P. Houtlosser, 131-159. Dordrecht: Kluwer (Argumentation Library 6).

Van Eemeren, F.H., and P. Houtlosser. 2004. More about fallacies as derailments of strategic maneuvering: The case of Tu Quoque. In Argumentation and its applications, ed. H.V. Hansen, C.W. Tindale, J.A. Blair, R.H. Johnson, and R.C. Pinto. Proceedings of the conference organized by the Ontario society for the study of argumentation, May 17-19, 2001, University of Windsor, CDROM. Windsor, ON: OSSA.

Van Eemeren, F.H., and P. Houtlosser. 2005. Theoretical construction and argumentative reality: An analytical model of critical discussion and conventionalised types of argumentative activity. In The uses of argument: Proceedings of a conference at McMaster University, ed. D. Hitchcock, 75-84. Hamilton: OSSA.

Walton, D.N., and E.C.W. Krabbe. 1995. Commitment in dialogue: Basic concepts of interpersonal reasoning. Albany, NY: State University of New York Press. 